were normal. Abdominal ultrasound unremarkable. Heart ultrasound: unremarkable. Neurological examination, muscle strength and reflexes are normal. EMG: no miopathic changes. ENG: normal. Rtg of lower extremities found calcifications of soft tissues. Bones with no destruction or osteolises. Biopsy: on subcutan adipose tissue are found multiple and confluent foci of calcification called Calcinosis. She is without treatment to now and exacerbation of changes has been detected.

Conclusion Since there were no systemic metabolic disorders, tissue injury, or other founded reason, and the diagnose of Calcinosis cutis idiopathica was made.

Acknowledgements to nurses of nephrology department.

\begin{tabular}{l}
\hline 630 NEUROPSYCHOLOGICAL OUTCOME IN CONGENITAL \\
HYPOTHYROIDISM IN AN ITALIAN COHORT: THE \\
DEVELOPMENTAL OUESTIONNAIRE FOR CH (DOCH)
\end{tabular}

doi:10.1136/archdischild-2012-302724.0630

'S Bargagna, ${ }^{2} \mathrm{~A}$ Olivieri, ${ }^{2} \mathrm{C}$ Fazzini, ${ }^{1} \mathrm{M}$ Bozza. ${ }^{1}$ Stella Maris Scientific Institute, Pisa; ${ }^{2}$ stituto Superiore Sanità, Rome, Italy

Background and Aims Several studies on neuropsychological outcome in early treated children with congenital hypothyroidism $(\mathrm{CH})$. have demonstrated the presence of developmental disorders, in particular motor abilities language, emotions 1.2.3 The aim of this study was to to individuate the most vulnerable developmental domains and which risk factors are significantly associated with a poor outcome. To this end we have developed a developmental questionnaire on $\mathrm{CH}(\mathrm{DOCH})$.

Methods The DOCH has been created with dichotomous answers giving a score which hinders the dispersion of data and makes it easy to fill-in for a person knowing the child (clinical psychologist, physician, parents). It consists of 49 questions, in 7 domains - motor skills, personal autonomy, language development, social development, behaviour, biorhythms, and success in school. This questionnaire was designed for an easy way to collect data on developmental milestones and neuropsychological outcome in a large cohort of children with $\mathrm{CH}$ and their age-matched controls.

Results All domains of our questionnaire show major impairments in children with $\mathrm{CH}$ than in controls, in particular in personal autonomy for the group with thyroidal agenesis and social development for ectopic glands.

Conclusions We hypothesize that children with a more severe outcome are more frequently those of mothers affected by clinical and subclinical forms of hypothyroidism during pregnancy.

Refernces Oerbeck B, et al. Congenital Hypothyroidism: Influence of Disease Severity and L-Thyroxine Treatment on Intellectual, Motor, and School-Associated outcomes in Young Adults. Pediatrics 2003; 4:923-930.

Rovet JF. Congenital Hypothyroidism: long-term outcome. Thyroid 1999; Neuropsychological Developmental Congenital C Child Neuropsychological 2002.

\section{INFLUENCE OF ANTHROPOMETRICAL AND MENTAL STATUSES ON OCCURRENCE OF BEHAVIOUR DISEASES AMONG CHILDREN OF SCHOOL AGE}

doi:10.1136/archdischild-2012-302724.0631

K Lepiatsila. Belarussian State Medical University, Minsk, Belarus

To estimate influence of the anthropometrical status and personal features on occurrence of psychosomatic frustration, in particular, eating disorder, among children of school age.

We studied 57 children (age $15 \pm 1.3$ years). They were interviewed with Toronto Alexithimia Scale (TAS), scale of Rotter, standardized questionnaire "Aim-Means-Result" (AMR), scale of Rean and divided into 3 groups on the basis of body mass index (BMI). 1) $\mathrm{A}(\mathrm{BMI}<19$ $\left.\left.\mathrm{kg} / \mathrm{m}^{2}, 2\right) \mathrm{B}\left(19 \mathrm{~kg} / \mathrm{m} 2<\mathrm{BMI}<24 \mathrm{~kg} / \mathrm{m}^{2}\right), 3\right) \mathrm{C}\left(\mathrm{BMI}>24 \mathrm{~kg} / \mathrm{m}^{2}\right)$.

Results Based on the TAS $41 \%$ of boys showed higher than normal rates of alexithymia (A $-40 \%, \mathrm{~B}-60 \%, \mathrm{C}-100 \%$ ). Among girls (75\%,50\%,43\% respectively). AMR: $87 \%$ b and $82 \%$ g can't substantiate their goals. $50 \%$ of children had psychological barriers. Low-energy potential was recorded in Groups A and C (17\% and $25 \%$ ). $66 \%$ girls and $88 \%$ boys of all groups indicated optimal results. Scale of Rotter. Boys of Group C were dominated by external locus of control. Girls of such group were dominated by internal locus of control of life. Motivational pole is not strongly marked in $61 \%$ of girls.

The analysis of TAS showed an increasing trend of alexithymia among boys (from $59 \%$ to $100 \%$ ) and lower among girls (from $75 \%$ to $43 \%$ ) with an increase in BMI. Boys with a BMI> $24 \mathrm{~kg} / \mathrm{m}^{2}$ prevailed external locus of control, the girls - internal locus of control. In analyzing the results of the questionnaire of Rean boys tended to reduce the motivation to succeed and grow with the increase of negative motivation with increasing BMI (success from $70 \%$ to $25 \%$ ).

\section{EARLY INTERVENTION OF VISUAL IMPAIRMENT MAY PROTECT ADAPTIVE BEHAVIOUR IN DOWN SYNDROME?}

doi:10.1136/archdischild-2012-302724.0632

${ }^{1} \mathrm{~A}$ Dressler, ${ }^{2} \mathrm{M}$ Bozza, ${ }^{2} \mathrm{~V}$ Perelli, ${ }^{3} \mathrm{~S}$ Bargagna. 'Division of General Neuropediatrics and Neonatology, Medical University Vienna, Vienna, Austria; ${ }^{2}$ RCCS-Stella Maris Institute, ${ }^{3}$ Stella Maris Institute, Pisa, Italy

Down syndrome (DS) is one the most common genetic disorders. Little is known about the impact of visual disorders in DS on daily life. Our aim was to study the relation between the incidence of ocular manifestations and adaptive behaviour.

Methods We performed a detailed medical history, including ocular disorders. We tested Hirschberg's corneal reflex method, observed eye movements during fixation of a slowly moving object, cover test, and assessed the Vineland Adaptive BehaviourScales, as well as the Coloured Progressive Matrices. 52 DS individuals with an age range of 19 to 52 years. Results. We observed a high incidence of ocular anomalies (refractive errors in $59.2 \%$, strabism in $51 \%$, motility disorders in $63.3 \%$ and congenital bilateral cataract in $16.2 \%$ ), not differing with age. The occurence of visual disorders did neither lead to total lower adaptive level nor show an influence on cognition. Daily living skills were significantly lower in individuals with not corrected disorders, but these individuals showed a significant high co-morbidity of autism with childhood onset. We observed a majority of individuals with an adaptive functioning above the average. Hyperopia and the presence of refractive errors were significantly more frequent in individuals with an adaptive level above the average. Conclusions. Visual disorders lead to a poorer performance in adaptive behaviour in individuals with DS and also autism. This suggests that early intervention on refractive errors and visuomotor skills helps in the acquisition of daily living activities, which remain stable over the life-span. Therapeutic options for cataract need to be addressed early.

\section{WHAT IS THE EFFECTIVENESS OF DIMETHYLGLYCINE IN TREATING AUTISTIC SYMPTOMS IN CHILDREN: A SYSTEMATIC REVIEW}

doi:10.1136/archdischild-2012-302724.0633

M Haroon, G Ryan, M Randell, J Wilson, T Khatau, CHARGE: Child Health Applied Research Group, East-midlands. Leicester Partnership Trust, Leicester, UK

Background and Aims Dimethylglycine, an amino-acid derivative, has been proposed as a treatment for Autism. A systematic review was conducted to synthesize the best evidence relating to this topic. 